Reply

\title{
Reply to Alizadeh's Letter to the Editor Re: Lu, P.Y. et al., Nutrients 2017, 9, 38
}

\author{
Pei-Ying Lu ${ }^{1}$, Long Shu ${ }^{2}$, Shan-Shan Shen ${ }^{1}$, Xu-Jiao Chen ${ }^{1, *}$ and Xiao-Yan Zhang ${ }^{2}$ \\ 1 Department of Geriatrics, Zhejiang Hospital, Xihu District, Hangzhou 310013, China; \\ lupy007@sina.com (P.-Y.L.); shenshan305@163.com (S.-S.S.) \\ 2 Department of Nutrition, Zhejiang Hospital, Xihu District, Hangzhou 310013, China; \\ shulong19880920@126.com (L.S.); zxy19740804@sina.com (X.-Y.Z.) \\ * Correspondence: lily197459@163.com; Tel.: +86-571-8159-5100; Fax: +86-571-8798-0175
}

Received: 6 July 2017; Accepted: 6 July 2017; Published: 7 July 2017

To the Editor:

We have read the letter by Alizadeh regarding our article entitled "Dietary Patterns and Pancreatic Cancer Risk: A Meta-Analysis" as published in Nutrients in January 2017 [1]. The aim of this meta-analysis was to assess the associations between whole-diet and the risk of pancreatic cancer.

First, we are grateful to Alizadeh et al. for alerting us to the methodological limitations in this manuscript. We accept the methodological limitations in the present meta-analysis. Thus, in this reply, we have endeavored to respond to the point highlighted by Alizadeh. In our analyses, 32 studies (13 studies reported the associations between alcohol intake and pancreatic cancer) were finally included. As Dr Alizadeh says, there are only seven studies [2-8] reporting the associations between whole-diet and the risk of pancreatic cancer. However, we cannot ignore the effect of food groups on the risk of pancreatic cancer, although they do not represent whole-diet. To our knowledge, the association of diet with the risk of pancreatic cancer has been inconclusive. Besides, although some studies have reported the decreased risk of pancreatic cancer associated with fruits and vegetables, an international panel of experts concluded that the evidence for the association of fruit and vegetable consumption in relation to pancreatic cancer risk is limited and inconsistent. Thus, to minimize error, the authors ensured that the defined dietary patterns were similar with regard to the main factor loadings of foods, which are consumed within those whole-diets. For example, the first pattern, named as the healthy pattern, is characterized as having high loadings of foods such as vegetables, fruits, whole grains, olive oil, fish, soy, poultry and low-fat dairy. The second pattern, named as the "western-type" pattern, is characterized by a high consumption of, e.g., red and/or processed meat, refined grains, sweets, high-fat dairy products, butter, potatoes and high-fat gravy, and low intakes of fruits and vegetables. Higher meat consumption may reflect a western dietary behavior and lifestyle. Thus, we considered the meat intake in the studies of Taunk et al. [9], Nöthlings et al. [10], and Anderson et al. [11] as a western/unhealthy dietary pattern.

In conclusion, we show in this reply that the issue raised by Alizadeh et al was not ignored. But our findings are useful as an exploratory meta-analysis to confirm the significant associations between diet and pancreatic cancer and add to the existing literature supporting the concept that diet plays an important role in the prevention of pancreatic cancer.

We are grateful to Alizadeh for bringing to our attention to the methodological limitations in the conduct of the meta-analysis, and for giving us an opportunity to reassess our work from his perspective.

Author Contributions: P.-Y.L., X.-J.C., L.S., S.-S.S. and X.-Y.Z. Co-authored this response.

Conflicts of Interest: The authors declared no conflict of interest. 


\section{References}

1. Lu, P.-Y.; Shu, L.; Shen, S.-S.; Chen, X.-J.; Zhang, X.-Y. Dietary patterns and pancreatic cancer risk: A meta-analysis. Nutrients 2017, 9, 38. [CrossRef] [PubMed]

2. Bosetti, C.; Turati, F.; Dal Pont, A.; Ferraroni, M.; Polesel, J.; Negri, E.; Serraino, D.; Talamini, R.; La Vecchia, C.; Zeegers, M.P. The role of mediterranean diet on the risk of pancreatic cancer. Br. J. Cancer 2013, 109, 1360-1366. [CrossRef] [PubMed]

3. Arem, H.; Reedy, J.; Sampson, J.; Jiao, L.; Hollenbeck, A.R.; Risch, H.; Mayne, S.T.; Stolzenberg-Solomon, R.Z. The healthy eating index 2005 and risk of pancreatic cancer in the NIH-AARP study. J. Natl. Cancer Inst. 2013, 105, 1298-1305. [CrossRef] [PubMed]

4. Nkondjock, A.; Krewski, D.; Johnson, K.C.; Ghadirian, P. Dietary patterns and risk of pancreatic cancer. Int. J. Cancer 2005, 114, 817-823. [CrossRef] [PubMed]

5. Michaud, D.S.; Skinner, H.G.; Wu, K.; Hu, F.; Giovannucci, E.; Willett, W.C.; Colditz, G.A.; Fuchs, C.S. Dietary patterns and pancreatic cancer risk in men and women. J. Natl. Cancer Inst. 2005, 97, 518-524. [CrossRef] [PubMed]

6. Inoue-Choi, M.; Flood, A.; Robien, K.; Anderson, K.E. Nutrients, food groups, dietary patterns and risk of pancreatic cancer in postmenopausal women. Cancer Epidemiol. Prev. Biomark. 2011, 20, 711-714. [CrossRef] [PubMed]

7. Bosetti, C.; Bravi, F.; Turati, F.; Edefonti, V.; Polesel, J.; Decarli, A.; Negri, E.; Talamini, R.; Franceschi, S.; La Vecchia, C. Nutrient-based dietary patterns and pancreatic cancer risk. Ann. Epidemiol. 2013, 23, 124-128. [CrossRef] [PubMed]

8. Chan, J.M.; Gong, Z.; Holly, E.A.; Bracci, P.M. Dietary patterns and risk of pancreatic cancer in a large population-based case-control study in the San Francisco Bay Area. Nutr. Cancer 2013, 65, 157-164. [CrossRef] [PubMed]

9. Taunk, P.; Hecht, E.; Stolzenberg-Solomon, R. Are meat and heme iron intake associated with Pancreatic cancer? Results from the NIH-AARP diet and health cohort. Int. J. Cancer 2016, 138, 2172-2189. [CrossRef] [PubMed]

10. Nöthlings, U.; Wilkens, L.R.; Murphy, S.P.; Hankin, J.H.; Henderson, B.E.; Kolonel, L.N. Meat and fat intake as risk factors for pancreatic cancer: The multiethnic cohort study. J. Natl. Cancer Inst. 2005, 97, 1458-1465. [CrossRef] [PubMed]

11. Anderson, K.E.; Sinha, R.; Kulldorff, M.; Gross, M.; Lang, N.P.; Barber, C.; Harnack, L.; DiMagno, E.; Bliss, R.; Kadlubar, F.F. Meat intake and cooking techniques: Associations with pancreatic cancer. Mutat. Res. Fundam. Mol. Mech. Mutagen. 2002, 506, 225-231. [CrossRef] 